Service learning students assisted with the activities. Through an online evaluation survey, over $90 \%$ of teachers assessed the program as very positive. One activity was assessed as neutral by all teachers, and this activity was revised. Teachers reported that $75 \%$ to $90 \%$ of students were highly engaged

Conclusions Schools rarely use arts-based approaches to target behaviour change, although they are a promising approach and schools increasingly seek ways to integrate arts into core education.

\section{Strategies and Policies}

\section{Post Tue 2.9}

\section{STRENGTHENING THE INJURY SURVEILLANCE SYSTEM BY ESTABLISHING A U-HEALTH-BASED SMART DOCTOR SYSTEM}

${ }^{1} \mathrm{IG} \mathrm{Kim},{ }^{2} \mathrm{HH}$ Paik, ${ }^{3} \mathrm{H}$ Joo. ${ }^{1}$ Executive Director of Songpa Public Health Centre, Korea; ${ }^{2}$ Safety Management Officer of Songpa Public Health Centre, Korea; ${ }^{3}$ Smart Doctor System Management Officer of Songpa Public Health Centre, Korea

\subsection{6/injuryprev-2016-042156.708}

Background Songpa District was initially designated as an international safe community in 2008 and re-designated in 2013. Its Injury Surveillance System (ISS) comprises the Web-based ISS, injury yearbook, and infant and child ISS for the high-risk group. An attempt was made to strengthen the ISS by using the $U$ Health-based Smart Doctor Program, which is being implemented by the Songpa Public Health Centre to more easily and extensively collect citizen injury data.

Description of the problem Methods previously used to collect the local community's injury data include home visits, requests to public and relevant organisations for materials, visits to locations with an injury risk environment, local resident surveys, injury reports of nursery facilities and materials from national statistical institutions. Materials of national statistical institutions were mostly on the entire nation, pointing to the need for more personnel and resource input to obtain local community-level data. There was thus a need to strengthen the ISS using the ubiquitous healthcare.

Results The U-Health-based Smart Doctor System is an information technology-based health management system that is customizable for individuals. Songpa District residents use kiosks to easily check their health information (physical data, blood pressure, BMI, etc.). Collected data is interfaced to the website and mobile phone application to enable real-time receipt of help from doctors and nutrition and exercise experts. This system is used by a great number of citizens, and is used to collect injury data along with health data to strengthen the local community's ISS.

Conclusions The U-Health-based Smart Doctor System is provided free based on Songpa District's independently developed program. It is regarded as an effective system for collecting resident health and injury data in the nation's large cities that have a good ubiquitous mobile environment. Also, system advancements can be made to obtain diverse information using big data.

\section{9 ANALYSIS OF THE SONGPA SAFETY DOCTOR PROGRAM BASED ON SOCIAL NETWORK ANALYSIS}

${ }^{1} \mathrm{JH}$ Paik, ${ }^{2} \mathrm{IG} \mathrm{Kim} .{ }^{1}$ Safety Management Officer of Songpa Public Health Centre, Korea; ${ }^{2}$ Executive Director of Songpa Public Health Centre, Korea

\subsection{6/injuryprev-2016-042156.709}

Background Since 2005, the Songpa District has implemented the Safety Doctor Program (SDP), which involves having a dedicated doctor for a nursery facility to quickly respond to safetyrelated incidents at nursery facilities. By analysing cooperative relations among local community members in a network that was established by the SDP, this study ascertains the characteristics of the safe community program network and defines the direction of development.

Methods A social network analysis survey was conducted on 233 people from the Songpa Public Health Centre (SPHC), Songpa Medical Association, and Songpa Nursery Facility Association that are participating in the SDP. This was followed by a network relations analysis using social network analysis indicators - centrality, centralization, density, and exchange relations.

Results First, from among the SDP members, the SPHC indicates the highest centrality (degree centrality: 0.650) and the highest centralization (in-degree centralization: 64.469\%), and thus leads the flow of information and resources.

Second, network density is overall low. Network density that excluded the SPHC $(0.9 \%)$ is lower than the network density that included the centre (1.2\%). If the SPHC does not participate in the SDP, several subgroups would emerge among the members, preventing the smooth flow of resources and information and resulting in weak exchange relations.

Third, exchange relations of the network that includes the SPHC consist of education, medical services, and public interests. A cooperation evaluation indicated a high level.

Conclusions The SDP member network is focused on the SPHC, but the Program has great significance in that it promoted discussions among local community member groups. The social network analysis results can be used to motivate local community members to engage in participation and cooperation, thus further developing the infant and child injury prevention program.

\section{\begin{tabular}{l|l}
710 & ROLE OF A CHAMPION ORGANISATION IN MAKING
\end{tabular} CHILD INJURY INTO A PRIORITY NATIONAL HEALTH AGENDA IN LOW-INCOME COUNTRY SETTING: BANGLADESH EXPERIENCES}

AKM Fazlur Rahman. Centre for Injury Prevention and Research, Bangladesh

\subsection{6/injuryprev-2016-042156.710}

Background Child injury is a major public health problem in low and middle income countries. According to a WHO estimate more than 630,000 children died due to injury globally in 2011 . In Bangladesh, injury is the leading cause of death for children after one year of age.

Description of the problem Although injury is a leading killer of children, in many countries, it remains an unrecognised, neglected health issues mainly due to lack of data, evidences for solution, and lack of advocacy and communication. Like many 